\title{
First Detection of Candidatus Xenohaliotis Californiensis, the Causative Agent of Withering Syndrome, in Japanese Black Abalone Haliotis discus discus in Japan
}

\author{
Ikunari Kiryu $^{1 *}$, Jun Kurita ${ }^{1 * *}$, Kei Yuasa ${ }^{1}$, Toyohiro Nishioka1, Yoshiko Shimahara ${ }^{1}$, \\ Takashi Kamaishi ${ }^{1}$, Mitsuru Ototake ${ }^{1}$, Norihisa Oseko ${ }^{1}$, Nahoko Tange ${ }^{2 * * *}$, \\ Masahiko Inoue ${ }^{3}$, Takashi Yatabe ${ }^{3}$ and Carolyn S. Friedman ${ }^{4}$ \\ ${ }^{1}$ National Research Institute of Aquaculture, Fisheries Research Agency, Mie 516-0193, Japan \\ ${ }^{2}$ Fish Farming Center, Department of Agriculture, Forestry and Fishery, Tottori Prefectural \\ Government, Tottori 689-0602, Japan \\ ${ }^{3}$ Tottori Fish Farming Association, Tottori 689-0602, Japan \\ ${ }^{4}$ School of Aquatic and Fishery Sciences, University of \\ Washington, Washington 98195, USA
}

(Received November 6, 2012)

\begin{abstract}
Withering syndrome (WS) is a chronic wasting disease in abalone caused by 'Candidatus Xenohaliotis californiensis', a Rickettsia-like organism (RLO). Japanese black abalone Haliotis discus discus (14-34 mm in shell length) experienced monthly mortality rates of 3 to 10\% from September 2010 to January 2011 with a cumulative mortality of $33 \%$ in a hatchery. Nine moribund animals were examined: five animals by histopathology and four by PCR. In histopathological examination, three animals exhibited basophilic, intracellular bacterial inclusions in the epithelium of the digestive tract. Severe infection was observed in the epithelium of the posterior portion of the esophagus of one animal. Morphological characteristics, and target tissues containing the inclusions were consistent with WS-RLO infection. In a PCR for 16S rRNA gene of WS-RLO, a specific fragment was amplified from all four animals, and nucleotide sequences of the amplicons were identical to that of the WS-RLO reported previously. The RLOs observed were conclusively identified as the agent of WS. Despite infection with the WS-RLO, our observations showed little degeneration of the digestive gland and shrinkage of the foot muscle both of which are critical pathological changes in WS. This is the first report of the WS-RLO found in Japanese black abalone in Japan.
\end{abstract}

Key words: withering syndrome, Candidatus Xenohaliotis californiensis, Haliotis discus discus, abalone, inclusion, esophagus

Withering syndrome (WS) is known to cause mortality in both wild and cultured abalone and the causative agent is 'Candidatus Xenohaliotis californiensis', a Rickettsia-like organism (RLO), which infects the epithelial cells of the digestive tract (Haaker et al., 1992; Friedman et al., 2000; Moore et al., 2000). The disease was first observed in black abalone (Haliotis cracherodii) in the Channel Islands, California, USA, in the mid-1980s (Haaker et al., 1992; Lafferty and Kuris, 1993), and resulted in dramatic declines, which contrib-

\footnotetext{
* Corresponding author

E-mail: ikunari@affrc.go.jp

** Present address: Headquarters, Fisheries Research Agency, Kanagawa 220-6165, Japan

*** Present address: Fishery Division, Fishery Development Bureau Department of Agriculture, Forestry and Fishery, Tottori Prefectural Government, Tottori 680-8570, Japan
}

uted to the listing of this species under the federal Endangered Species Act in 2009 (National Oceanic and Atomospheric Adminstration, U. S. Department of Commerce, 2009). Infection with the WS-RLO is listed as notifiable in the International Aquatic Animal Health Code of the Office International des Epizooties, O.I.E. (O.I.E., 2009).

Undoubtedly, WS-RLO has a wide host range within the genus Haliotis and infects juvenile and adult abalone (VanBlaricom et al., 1993; Gardner et al., 1995; Friedman et al., 1997, 2002; Braid et al., 2005; Friedman et al., 2007). Natural infections have been observed in black abalone $(H$. cracherodii), white abalone $(H$. sorenseni), red abalone $(H$. rufescens), pink abalone $(H$. corrugata), green abalone $(H$. fulgens), small abalone $(H$. diversicolor supertexta), the European abalone $(H$. tuberculata) in the wild or in culture faciliti- 
es, as well as flat abalone ( $H$. wallalensis) and Japanese abalone $H$. discus hannai following laboratory challenges (Moore et al., 2000, 2003; Balseiro et al., 2006; Garcia-Esquivel et al., 2007; Friedman et al., 2007; O.I.E., 2009; Wetchateng et al., 2010).

The geographical range of WS is suspected to be broader than currently reported as infected animals have been transported among countries by the worldwide trade of abalone (O.I.E., 2009). Indeed, the disease has been reported in Europe (Balserio et al., 2006) and recently in Asia including Thailand, Taiwan and the People's Republic of China, where WS-RLOs were found in healthy, normal $H$. diversicolor supertextra by survey, and only resulting in asymptomatic infection (Wetchateng et al., 2010).

In September 2010, mortality occurred in cultured Japanese black abalone (H. discus discus) in Japan. Relatively high intensity infection by RLO was observed in the epithelium of the posterior portion of the esophagus (postesophagus), the intestinal epithelium and, to a lesser extent, in the epithelium of the transport ducts in the digestive gland of abalone. Although a convincing correlation between mortality and infection with WSRLO is not well established in the present study, this is the first report that the WS-RLO has been found in abalone in Japan and that Japanese black abalone $(H$. discus discus) can be naturally infected with WS.

\section{Materials and Methods}

History of abalone culture and sampling schedule

Japanese black abalone ( $H$. discus discus) were hatched at the Tottori Prefectural Fish Farming Center in December 2009, and were reared using conventional hatchery methods. Animals received a flow-through mixture of UV-irradiated seawater from two marine sources: a deep seawater well and filtered surface water. After six months of growth, 130,000 juvenile abalone $(8-18 \mathrm{~mm})$ were divided among six tanks, each of seven ton capacity, according to the size of the animals, and were fed with a pelleted diet ('Awabi 3', Nosan Co.). Animals of similar sizes were held in each tank containing 15,000-25,000 juveniles. The temperature of the water was recorded periodically (at least five times per week). Mortalities in each tank were periodically recorded from September 2010. Animals investigated in this study ranged from 14-34 $\mathrm{mm}$ in maximum shell length.

Relatively high mortality was found in one of the six tanks. The first round of sampling was conducted on January 25, 2011, and nine moribund animals were collected from this tank and sent to our laboratory. Of these, five animals were used for histopathological observation and four were submitted for molecular biological analysis, by PCR and sequence analysis.

Since WS-RLOs were found in abalone in the first sampling round in January, all animals in the single affected tank were disposed of immediately. Instead of using the diseased animals, other batches of abalone from the same spawn were used in further investigations. Abalone from the remaining five tanks had been raised under the same conditions as those in the tank containing diseased abalone described above. For the second round of sampling, apparently healthy animals ( $n=44$ per tank) were randomly collected from each of five tanks on March 22, 2011, sent to our laboratory and processed for histopathology ( $n=9$ per tank) and molecular biology ( $n=35$ per tank).

\section{Gross observations}

The abalone in tanks were visually observed for changes in feeding, behavior and appearance. The general appearance of the tank water was also recorded.

\section{Histological observation and RLO infection intensity}

Each of 50 animals, consisting of five moribund animals from the first sampling round and $45(n=9$ per tank) healthy animals from the second sampling round, was preserved in Davidson's solution (Shaw and Battle, 1957) and processed for routine paraffin histology. Three $\mu \mathrm{m}$ sections were taken from the paraffin embedded tissue blocks and stained with either hematoxylin and eosin (H\&E), or a combination of May-Grünwald and Giemsa stains. Most tissues present in abalone were represented, and were examined by light microscopy. Each slide typically contained buccal cavity, esophagus, crop, stomach, digestive gland, intestine, rectum, mantle, gill, both left and right kidneys, heart, foot muscle and nerve system.

The intensity of infection by RLO was rated for the postesophagus, crop, digestive gland and intestine in each animal based on histological observation at $200 \times$ magnification, following the method of Friedman et al. (1997). Namely, no visible RLO inclusions in the field were rated as 0,1 to 10 inclusions of RLO per field of view were rated as 1,11 to 100 inclusions per field were rated as 2 and more than 100 inclusions per field were rated as 3 .

\section{$P C R$ and sequence analysis}

Since RLO inclusions were histologically observed in the digestive tract, PCR was conducted to detect the pathogen, "Candidatus Xenohaliotis californiensis". Animals used for PCR $(n=179)$ consisted of four moribund abalone from the first sampling round and 175 ( $n=35$ per tank) healthy abalone from the second sampling round. A range of tissues were taken from the abalone, including the postesophagus, intestine and digestive gland, which are the major sites of infection for this pathogen (Friedman et al., 2000). These tissues were individually processed for DNA extraction: four 
abalone from the first sampling round and 25 abalone ( $n=5$ per tank) collected from five tanks, from the second sampling round. For the remaining 150 abalone ( $n=30$ per tank) from the second sampling timepoint, the tissues of five animals originating from the same tank were pooled for cost-saving measures following the method described by the O.I.E. (O.I.E., 2009), and subjected to DNA extraction. DNA was extracted using the Maxwell 16 automated system (Promega) following the manufacturer's recommendations, and the extracted DNA was dissolved in a final volume of 300 $\mu \mathrm{L}$ of elution buffer. PCR amplification of the $16 \mathrm{~S}$ rDNA of "Candidatus Xenohaliotis californiensis" was performed with the specific primer set, RA 5.1 (5'-GTT GAA CGT GCC TTC AGT TTA C-3') / RA 3.6 (5'-ACT TGG ACT CAT TCA AAA GCG GA-3') as developed by Andree et al. (2000). PCRs were run in $20 \mu \mathrm{L}$ volumes made up of: $1 \times$ PCR buffer 'Ampdirect' (Shimadzu), $0.2 \mathrm{~mm}$ of each dNTP, $0.5 \mu \mathrm{m}$ of each primer, $0.5 \mathrm{U}$ of exTaq (Takara) and $2 \mu \mathrm{L}$ of extracted DNA from each sample. The buffer 'Ampdirect' was used to diminish any influence of amplification inhibitors derived from samples during the process of DNA extraction. The PCR conditions were: $95^{\circ} \mathrm{C}$ for $5 \mathrm{~min}$, then 40 cycles $\left(95^{\circ} \mathrm{C}\right.$ for $1 \mathrm{~min}, 62^{\circ} \mathrm{C}$ for $30 \mathrm{~s}$, and $72^{\circ} \mathrm{C}$ for $30 \mathrm{~s}$ ) with a final extension step at $72^{\circ} \mathrm{C}$ for $10 \mathrm{~min}$. Amplified fragments of DNA were separated on a $2 \%$ agarose gel containing ethidium bromide and examined using UV illumination. When an amplified fragment was seen at the expected size of $158 \mathrm{bp}$ in an agarose gel, an aliquot of the amplified DNA was submitted for nucleotide sequence analysis to confirm sequence identity with "Candidatus Xenohaliotis californiensis". The DNA fragments were directly sequenced from the PCR product by means of the dideoxychain termination method using BigDye Terminator v3.1 (Applied Biosystems) following the manufacturer's instructions, and the nucleotide sequence was determined with an automated sequencer, the ABI PRISM 3130 xI Genetic Analyzer (Applied Biosystems). Sequence data were analyzed using the software 'GENETYX' (Software Development Co., Ltd) and aligned with the WS-RLO sequence (GenBank Accession number AF133090).

\section{Results}

Temperature and Mortality records

The temperature of the seawater was $13-14^{\circ} \mathrm{C}$ from February to the end of April 2010, rose gradually by $1-3^{\circ} \mathrm{C}$ per month in May and reached $21^{\circ} \mathrm{C}$ in September, and the temperature was stable at $21^{\circ} \mathrm{C}$ for a month (Fig. 1A). After this period temperatures declined gradually by $1-2^{\circ} \mathrm{C}$ per month and reached $15.5^{\circ} \mathrm{C}$ in February 2011.

In the tank used for the first sampling round, a high mortality rate was first found in September 2010, when

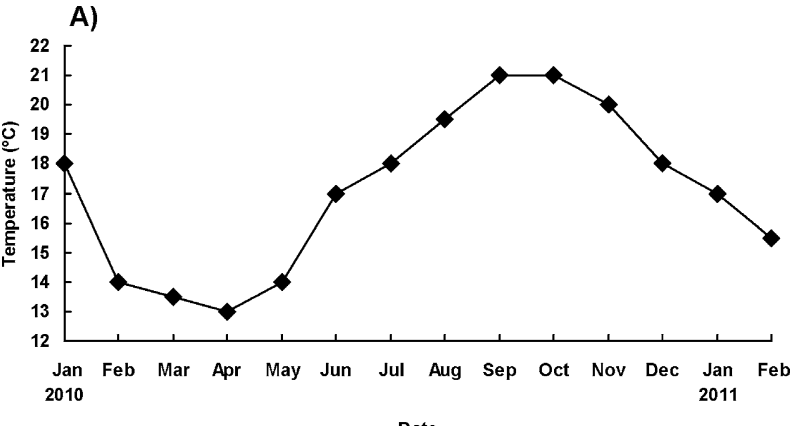

B)

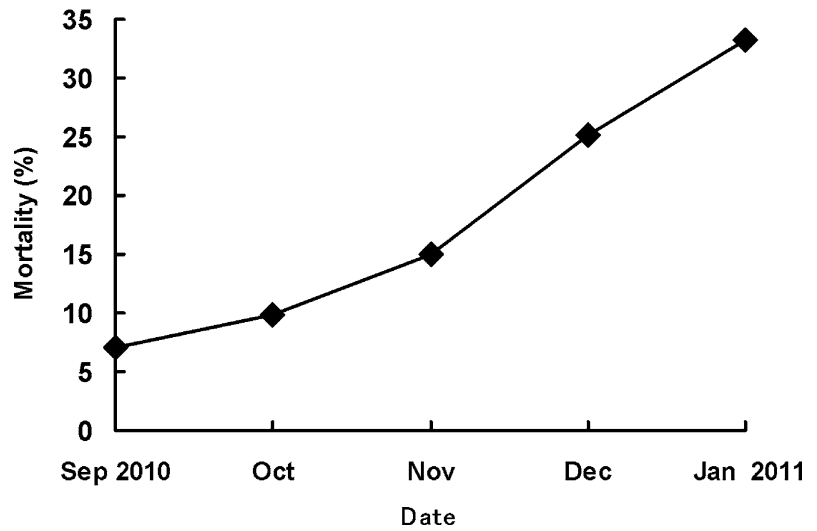

Fig. 1. Monthly seawater temperature (A) and cumulative mortality (B) in cultured Japanese black abalone (Haliotis discus discus). Temperature measured on the $1^{\text {st }}$ day of every month is shown. Cumulative mortality calculated at the end of each month is shown. A high rate of mortality was recorded in one tank from September 2010 that corresponded with the highest monthly average temperature. Mortality in each month is $7.0 \%$ in September, $2.9 \%$ in October, $5.1 \%$ in November, $10.2 \%$ in December and $8.0 \%$ in January.

7.0\% of the abalone died (Fig. 1B). Losses continued through January 2011, with monthly mortality ranging from 3 to 10\%: $2.9 \%$ in October, $5.1 \%$ in November, $10.2 \%$ in December and $8.0 \%$ in January. Thus, 6,641 of 20,000 abalone died, and a mortality over five months was $33.2 \%$. This relatively high-mortality was limited to one of six tanks.

For the other five tanks used in the second round of sampling, losses were within the range considered normal for abalone of this size at this research station (N. Tange, M. Inoue and T. Yatabe pers. obs.) with an approximately $9.5 \%$ cumulative mortality for five months of culture through January 2011. No spike in, or abnormal, mortalities were observed in abalone in any of these five tanks.

Gross pathology of abalone in the tank used for the first sampling round

Abalone exhibited anorexia during the high mortality period of the tank for the first round of sampling from September 2010 to January 2011. The debilitated ani- 
mals migrated to the water surface and tended to adhere to the shells of other abalone, lying on top of one another, and subsequently ceased movement. The water surface became covered with a thin mucuslike layer, presumably due to the secretion of abundant mucus from affected animals. Those signs were not observed in abalone of the other five tanks where no elevated losses were recorded. The characteristic clinical sign of withering syndrome, namely an atrophied foot, was not observed in any animals.
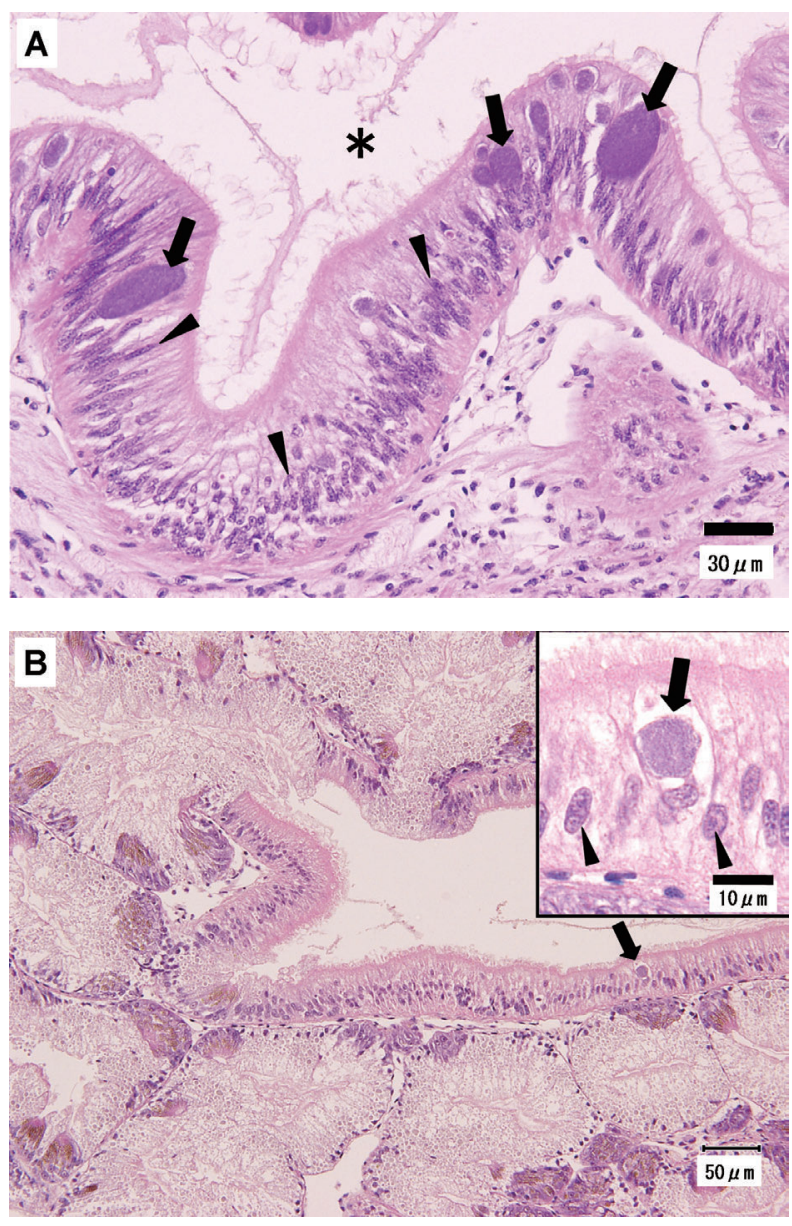

Fig. 2. Tissue section of the posterior portion of the esophagus (PE) (Fig. 2A) and the digestive gland (Fig. 2B) of a Japanese black abalone (Haliotis discus discus) infected with withering syndrome-Rickettsia-like organism (WS-RLO). This animal was collected in the first round of sampling and had the highest intensity of infection with WS-RLO, rank 3 (see Table 1). Note numerous basophilic bacterial inclusion bodies (arrows) observed in the epithelium of the PE in A. In $\mathrm{B}$, one inclusion (arrow) is observed in the epithelium of a transport duct. Inset right above shows the magnified inclusion. Any histopathological changes are not observed in the digestive gland (B). Arrowheads and an asterisk indicate the nucleus of the epithelial cells and the lumen of the esophagus, respectively. (Hematoxylin \& eosin).

\section{Histopathological observation}

Bacterial colonies were observed in the epithelial cells of the postesophagus in three out of five moribund animals taken in the first round of sampling (Fig. 2). Intracellular bacterial inclusions, the RLO inclusions, were basophilic (dark violet or light purple with $\mathrm{H} \& \mathrm{E}$ ), measured up to $40 \mu \mathrm{m}$ across, and were round or ovoid. The number of RLO inclusions was used to rate the intensity of infection, and the highest, ranked 3, was found in the postesophagus of one moribund animal (Fig. 2A), in which the inclusions were also observed in the epithelial cells of the intestine, crop and transport duct in the digestive gland (Fig. 2B).

Similarly the RLO inclusions were also observed in the epithelial cells of the digestive tract of 11 of 45 healthy abalone taken in the second round of sampling. Inclusions were found in two or three animals per tank. A relatively high intensity of infection, ranked 2 , was observed in the postesophagus and/or intestine of seven animals (Table 1 ).

To summarize the results of the distribution of the RLO inclusions in abalone from both rounds of sampling, RLOs were distributed among digestive epithelia as follows: $n=14$ in the postesophagus, $n=5$ in the intestine, $n=1$ in the crop and $n=2$ in the transport duct of the digestive gland (Table 1). The RLO inclusions were not found in tissues other than the epithelial cells of the digestive tract. Degeneration in the digestive gland and reduction of the foot muscle fibers were not observed, and those tissues showed normal morphology in all animals investigated in this study. No other notable pathological changes or pathogens were

Table 1. Distribution and intensity of "Candidatus Xenohaliotis californiensis", the causative agent of withering syndrome, in Japanese black abalone (Haliotis discus discus)

\begin{tabular}{cccccc}
\hline Sampling date & $\begin{array}{c}\text { Number of } \\
\text { animals }\end{array}$ & PE & IN & CR & TD \\
\hline January 25th & 1 & 3 & 2 & 2 & 1 \\
(the first round & 2 & 1 & 0 & 0 & 0 \\
of sampling) & 2 & 0 & 0 & 0 & 0 \\
\hline & 2 & 2 & 2 & 0 & 0 \\
March 22nd & 1 & 2 & 1 & 0 & 0 \\
(the second & 1 & 2 & 0 & 0 & 1 \\
round of & 3 & 2 & 0 & 0 & 0 \\
sampling) & 1 & 1 & 1 & 0 & 0 \\
& 3 & 1 & 0 & 0 & 0 \\
& 34 & 0 & 0 & 0 & 0 \\
\hline
\end{tabular}

Intensity of infection by the rickettsia-like organism (RLO) of Candidatus Xenohaliotis californiensis is rated based on histological observation of the RLO inclusions at $200 \times$ magnification. A rank of $0,1,2$ or 3 in each tissue indicates numbers of the inclusions per field of view: 0 , no inclusions; 1, 1-10 inclusions; 2, 11-100 inclusions; 3, > 100 inclusions. $\mathrm{PE}$, posterior portion of esophagus; IN, intestine; CR, crop; TD; transport duct in digestive gland. 
found.

\section{$P C R$ and sequence analysis}

A 158-bp PCR product, with a sequence identical to that of "Candidatus Xenohaliotis californiensis" was amplified from the DNA extracted from all four $(100 \%)$ moribund animals taken at the first sampling round (Fig. 3 ). For the second round of sampling, PCR-positive results were obtained from 20 out of $25(80 \%)$ healthy animals, and three to five positive animals were obtained per tank. Nucleotide sequences of these 24 PCR products were identical to those of the WS-RLO (GeneBank accession number AF133090). Additionally, RLO DNA was amplified from 28 of the 30 pooled samples (5 animals per pool) taken in the second round

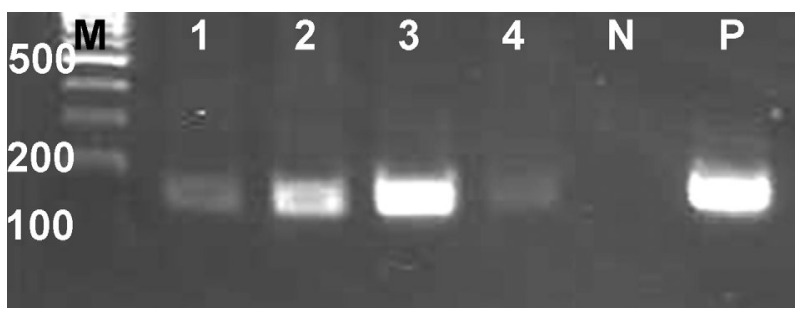

Fig. 3. Agarose gel (2\%) electrophoresis of PCR products amplified from DNA extracted from the digestive tract of abalone using primers specific for the etiologic agent of withering syndrome, yielding a $158 \mathrm{bp}$ product. Lane M, DNA molecular marker; Lane 1 to 4 , samples of moribund Japanese black abalone (Haliotis discus discus) collected in January 25; Lane N, negative control (non-template); Lane P, RLO-infected red abalone.

of sampling, with the two negative samples originating from two different tanks.

\section{Discussion}

Marked losses of cultured juvenile abalone $\mathrm{H}$. discus discus were experienced in a single tank, coinciding with elevated temperatures during the summer in Japan. Nine moribund animals were examined and both microscopic and molecular assays revealed the presence of the causative agent of withering syndrome, "Candidatus Xenohaliotis californiensis". The highest intensity of WS-RLO infection, rank 3, was microscopically observed in one moribund animal, and all of moribund animals (4/4) were positive by PCR for the causative agent of WS. These data suggest that infections with WS-RLO and associated disease may be a cause of this mortality.

A mechanism for the pathogenesis of WS in red abalone and black abalone $(H$. cracherodii) (Moore et al, 2000; Friedman et al., 2002) has been proposed. WS-RLOs first infect the epithelial cells of the postesophagus and proliferate in the cells, and then induce morphological changes in the digestive gland via metaplasia of the terminal digestive tubes to transport ducts. Terminal tubes re-differentiate or are replaced by proliferating duct tissues. The WS-RLO is able to further infect this metaplastic tissue. Shrinkage of the terminal tubes surrounded by connective tissues is conspicuous and metaplasia is less in black abalone $(H$. cracherodii) (Friedman et al., 2002). Ultimately the digestive gland loses its key function of nutrient acquisition, making this a fatal disease as abalone absorb nutrition in the digestive gland and not in the intestine (Voltzow, 1994). In the first sampling round of this study, however, WSRLOs were found in the epithelium of the digestive gland transport ducts in one moribund animal and no morphological changes were observed in the digestive gland of any animal investigated. Our observations suggest that, while WS may not have been the direct cause of mortality observed in the first tank sampled at this facility, it may have been a contributing factor (e.g. by negatively impacting abalone health). The stress of WS may also influence growth and reproduction (Vilchis et al., 2005; Rogers-Bennett et al., 2010).

Susceptibility to WS-RLO infection and development of subsequent disease may vary among species and temperature. Following infection, mortality rates at $18-20^{\circ} \mathrm{C}$ are $85-100 \%$ (Friedman et al., 1997, 2002) and 15-64\% (Moore et al., 2000; Braid et al., 2005; Vilchis et al., 2005; Moore et al., 2011) for black abalone (H. cracherodii) and red abalone, respectively. Black abalone $(H$. cracherodii) are the most susceptible to both infection and disease development, followed by red and green abalone. Many scientists agree that elevated temperature $\left(\sim 18^{\circ} \mathrm{C}\right)$ is an important factor for the emergence of WS in red abalone and that clinical signs and intensity of infection increase with temperature (Moore et al., 2000; Braid et al., 2005; Vilchis et al., 2005; Moore et al., 2011). WS is capable of infecting green abalone but no mortality occurred at $18-20^{\circ} \mathrm{C}$ (Vilchis et al., 2005; Moore et al., 2009). Green abalone only showed signs of WS and experienced mortality when held at elevated temperatures of $25^{\circ} \mathrm{C}$ (GarciaEsquivel et al., 2007), suggesting that the WS-RLO has a wider thermal range than originally observed in infections in abalone with cooler thermal optima (e.g. red abalone). In this study, we observed WS-RLOs in the epithelial cells in the digestive tract of Japanese abalone $\left(H\right.$. discus discus) kept at under $21^{\circ} \mathrm{C}$, suggesting that the WS-RLO could multiply at that temperature in this species, however the optimum temperature for development of WS infection in this species is still unknown.

Losses of abalone in the five tanks that experienced low level mortality were within the usual range for this facility. These animals lacked common gross clinical signs but the WS-RLO was detected in the second sampling period. In addition, neither high intensity of 
infection with WS (e.g. rank 3 in one moribund animal from the first sampling round), nor morphological changes in the digestive gland were observed in 45 healthy animals by microscopy. These results suggest that the losses found in the five tanks may be due to stress under culture, but not WS.

The origin of the RLOs found in the present study is unknown. Wetchateng et al. (2010) suggested that WS-RLOs found in small abalone in Asia originated from California. Although Japanese abalone were commonly moved from other culture facilities to the farm examined in the present study, imported abalone were not dealt with at this facility and there was no evidence of direct contact between the cultured abalone and any imported abalone. By contrast, many species of imported live abalone are available in Japan and the history of trade in red abalone in Japan was described by the O.I.E. (2009). We speculate that the pathogen was obtained from imported abalone by animal to animal transfer.

In our histological observation of abalone from both rounds of sampling, WS-RLOs were predominantly found in the postesophagus, followed by the intestine and less frequently in the digestive gland and crop. The findings from examination of the postesophagus are compatible with those seen in black $(H$. cracherodii), red, green and small abalone (Friedman et al., 2000; Moore et al., 2000, 2009; Wetchateng et al., 2010), suggesting that, as in other species observed to date, the postesophagus is the major target organ for WS-RLO proliferation. The intestine is the second major target organ in Japanese black abalone ( $H$. discus discus) and this pattern of infection differs from that observed in black $(H$. cracherodii) and small abalone, in which the second target tissue is the digestive gland (Friedman et al., 2000; Wetchateng et al., 2010). These observations illustrate that infection patterns may vary among species.

In this study, it was not confirmed that the WS-RLO is pathogenic to Japanese black abalone $(H$. discus discus) and induces mortality. Challenge experiments should be performed to determine the pathogenicity of the WS-RLO to the abalone (H. discus discus). However, it is difficult to conduct successful challenge tests of WS. Culture of the RLO is not yet possible, and cohabitation with infected animals is generally accepted for challenge tests. Long experimental periods of at least 3 months (Friedman et al., 1997), and usually from 220 days to 447 days (Moore et al., 2009) are required due to the chronic wasting disease nature of WS. Our challenge tests are on-going, using survivors of this mortality episode, and will provide more information regarding susceptibility of Japanese abalone to WS in future. This study is the first report of WS-RLOs found in Japanese black abalone $(H$. discus discus) in Japan.

\section{Acknowledgments}

The authors express their gratitude to the staff of Friedman's laboratory, University of Washington, Seattle, USA, for providing techniques and knowledge concerning the disease of withering syndrome. This study was supported by grants from the Food Safety and Consumer Affairs Bureau, the Ministry of Agriculture, Forestry, and Fisheries of Japan.

\section{References}

Andree, K. B., C. S. Friedman, J. D. Moore and R. P. Hedrick (2000): A polymerase chain-reaction for detection of genomic DNA of a Rickettsiales-like prokaryote associated with withering syndrome in black abalone (Haliotis cracherodii). J. Shellfish Res., 19, 213-218.

Balseiro, P., R. Aranguren, C. Gestal, B. Novoa and A. Figueras (2006): Candidatus Xenohaliotis californiensis and Haplosporidium montforti associated with mortalities of abalone Haliotis tuberculata cultured in Europe. Aquaculture, 258, 63-72.

Braid, B. A., J. D. Moore, T. T. Robbins, R. P. Hedrick, R. S. Tjeerdema and C. S. Friedman (2005): Health and survival of red abalone, Haliotis rufescens, under varying temperature, food supply, and exposure to the agent of withering syndrome. J. Invertebr. Pathol., 89, 219-231.

Friedman, C. S., M. Thomson, C. Chun, P. L. Haaker and R. P. Hedrick (1997): Withering syndrome of the black abalone, Haliotis cracherodii (Leach): water temperature, food availability, and parasites as possible causes. J. Shellfish Res., 16, 403-411.

Friedman, C. S., K. B. Andree, K. Beauchamp, J. D. Moore, T. T. Robbins, J. D. Shields and R. P. Hedrick (2000): "Candidatus Xenohaliotis californiensis," a newly described pathogen of abalone, Haliotis spp., along the West Coast of North America. Int. J. Syst. Evol. Microbiol., 50, 847-855.

Friedman, C. S., W. Biggs, J. D. Shields and R. P. Hedrick (2002): Transmission of withering syndrome in black abalone, Haliotis cracherodii Leach. J. Shellfish Res., 21, 817-824.

Friedman, C. S., B. S. Benjamin, E. S. Robyn and B. M. Thomas (2007): Oxytetracycline as a tool to manage and prevent losses of the endangered white abalone, Haliotis sorenseni, due to withering syndrome. J. Shellfish Res., 26, 877-885.

Garcia-Esquivel, Z., S. Montes-Magallon and M. A. GonzalesGomez (2007): Effect of temperature and photoperiod on the growth, feed consumption, and biochemical content of juvenile green abalone, Haliotis fulgens, fed on a balanced diet. Aquaculture, 262, 129-141.

Gardner, G. R., J. C. Harshbarger, J. Lake, T. K. Sawyer, K. L. Price, M. D. Stephenson, P. L. Haaker and H. A. Togstad (1995): Association of prokaryotes with symptomatic appearance of withering syndrome in black abalone Haliotis cracherodii. J. Invertebr. Pathol., 66, 111-120.

Haaker, P. L., H. Parker, D. V. Togstad, D. V. Richards, G. E. Davis and C. S. Friedman (1992): Mass mortality and withering syndrome in black abalone Haliotis cracherodii, in California. In: "Abalone of the world" (ed. by S. A. Shepherd, M. J. Tegner and S. A. Guzman del Proo), Blackwell Sci. Oxford, pp. 214-224.

Lafferty, K. D. and A. M. Kuris (1993): Mass mortality of abalone 
Haliotis cracherodii on the California Channel Islands: test of epidemiological hypotheses. Mar. Ecol. Prog. Ser., 96, 239-248.

Moore, J. D., T. T. Robbins and C. S. Friedman (2000): Withering syndrome in farmed red abalone, Haliotis rufescens: thermal induction and association with a gastrointestinal Rickettsiales-like procaryote. J. Aquat. Anim. Health, 12, 26-34.

Moore, J., T. Robbins, C. Friedman, N. Hooker, T. McCormick and M. Neuman (2003): Preliminary pathological investigation of the white abalone, Haliotis sorenseni. J. Shellfish Res., 22, 345-346.

Moore, J. D., C. I. Juhasz, T. T. Robbins and L. I. Vilchis (2009): Green abalone, Haliotis fulgens, infected with the agent of withering syndrome do not express disease signs under a temperature regime permissive for red abalone, Haliotis rufescens. Mar. Biol., 156, 2325-2330.

Moore, J. D., B. C. Marshman and C. S. Y. Chun (2011): Health and survival of red abalone Haliotis rufescens from San Miguel Island, California, USA, in a laboratory simulation of La Niña and El Niño conditions. J. Aquat. Anim. Health, 23, 78-84.

National Oceanic and Atomospheric Adminstration, U. S. Department of Commerce (2009): Endangered and Threatened Wildlife and Plants; Endangered Status for Black Abalone. Federal Register, 74, 1937-1946.

Office Internationale des Epizooties (2009): Infection with Xenohaliotis californiensis. In: Manual of Diagnostic
Tests for Aquatic Animals 2009. World Organisation for Animal Health, Paris, pp. 366-377.

Rogers-Bennett, L., R. F. Dondanville, J. D. Moore and L. I. Vilchis (2010): Response of red abalone reproduction to warm water, starvation, and disease stressors: implications of ocean warming. J. Shellfish Res., 29, 599-611.

Shaw, B. L. and H. I. Battle (1957): The gross and microscopic anatomy of the digestive tract of the oyster Crassostrea virginica (Gmelin). Can. J. Zool., 35, 325-347.

VanBlaricom, G. R., J. L. Ruediger, C. S. Friedman, D. D. Woodard and R. P. Hedrick (1993): Discovery withering syndrome among black abalone populations at San Nicolas Island, California. J. Shellfish Res., 12, 185-188.

Vilchis, L. I., M. J. Tegner, J. D. Moore, C. S. Friedman, K. L. Riser, T. T. Robbins and P. K. Dayton (2005): Effects of ocean warming on the growth, reproduction, and survivorship of red and green abalone in Southern California: implications for restoration and recovery of depleted stocks. Ecol. Appl., 15, 469-480.

Voltzow, J. (1994): Gastropoda: Prosobranchia. In: "Microscopic anatomy of invertebrates, volume 5" (ed. by F. W. Harrison and A. J. Kohn), Wiley-Liss, New York, pp. $111-252$.

Wetchateng, T., C. S. Friedman, N. A. Wight, P. Lee, P. H. Teng, S. Sriurairattana, K. Wongprasert and B. Withyachumnarnkul (2010): Withering syndrome in the abalone Haliotis diversicolor supertexta. Dis. Aquat. Org., 90, 69-76. 